\title{
Photoluminescence Spectroscopy of $\mathrm{ZnO}$ and $\mathrm{TiO}_{2}$ Pigments
}

Ryan Beams ${ }^{1}$, Edward P. Vicenzi ${ }^{1,2}$, Scott Wight ${ }^{1}$, Thomas Lam ${ }^{2}$, Stephanie Barnes ${ }^{3}$, Jia-Sun Tsang ${ }^{2}$, and Stephan J. Stranick ${ }^{1}$

${ }^{1}$ National Institute of Standards and Technology, Gaithersburg, MD USA

${ }^{2}$ Museum Conservation Institute, Smithsonian Institution, Suitland, MD, USA

${ }^{3}$ Library and Archives Canada, Gatineau, Quebec, Canada

In the late $19^{\text {th }}$ and early $20^{\text {th }}$ century zinc oxide $(\mathrm{ZnO})$ became available as an inexpensive alternative to lead white $\left[2 \mathrm{PbCO}_{3} \cdot \mathrm{Pb}(\mathrm{OH})_{2}\right]$ as a white pigment. However, poor chemical and mechanical properties for $\mathrm{ZnO}$ pigments have proved problematic in the field of painting conservation, as a result, $\mathrm{TiO}_{2}$ has supplanted $\mathrm{ZnO}$ white given its superior opacity and greater chemical stability in paints [1]. The development of additional noncontact and nondestructive methods for identifying $\mathrm{ZnO}$ and $\mathrm{TiO}_{2}$ in historical paintings that may contain mixtures of the two pigments is of clear value. Recently, timeresolved photoluminescence (PL) spectroscopy and microscopy has shown promise for understanding incipient alteration of $\mathrm{ZnO}$ in paintings [2,3]. Here we demonstrate that two-photon fluorescence lifetime imaging (FLIM) over selective spectral regions provides an additional novel method for the discrimination between these two white pigments in a painting cross section.

FLIM images were acquired using a NIST-built two-photon microscope. The sample was excited using a femtosecond Ti:sapphire laser centered at $750 \mathrm{~nm}$ with a repetition rate of $20 \mathrm{MHz}$ to provide a sufficient time window for longer lifetime PL processes. The laser was focused onto the sample using a high numerical aperture air objective $(0.95 \mathrm{NA})$ with a lateral resolution of $\approx 400 \mathrm{~nm}$. Images were acquired by rastering the sample using a piezo scan-stage. The resulting PL was collected using the same objective and sent a detector for time-correlated single photon counting. Photon arrival time histograms were collected at each pixel and fit to create lifetime images. X-ray imagery was collected with an FEI Apreo SEM operated at $9 \mathrm{kV}$ in variable pressure mode $\left(\mathrm{P}_{\mathrm{H} 20}=50 \mathrm{~Pa}\right)$ using dual Bruker XFlash $6 \mid 60$ silicon drift detectors [4].

PL spectra for pigment separates $\left(\mathrm{ZnO}\right.$, and $\left.\mathrm{TiO}_{2}\right)$ and a paint filler $\left(\mathrm{CaCO}_{3}\right)$ are shown in Figure $1 \mathrm{a}$. $\mathrm{ZnO}$ exhibits strong luminescence in the UV, which can be exploited to identify $\mathrm{ZnO}$ in the presence of other pigments and fillers. In addition to the spectral specificity, the lifetime characteristics also provide a fingerprint. Figure $1 \mathrm{~b}$ shows histograms of the weighted average lifetime in the $400 \mathrm{~nm}-410 \mathrm{~nm}$ spectral region. $\mathrm{ZnO} \mathrm{PL}$ is the dominant signal in this wavelength range. $\mathrm{The}^{\mathrm{TiO}} 2$ is several orders of magnitude weaker and has a shorter lifetime in this band, while $\mathrm{CaCO}_{3}$ lifetime data was not detectable. This indicates the separates can be identified using lifetime in this spectral region. As a result, FLIM provides a straight forward approach for identifying $\mathrm{ZnO}$ and $\mathrm{TiO}_{2}$ in paintings. To evaluate the discriminating capability of PL, we acquired a FLIM image of a painting cross section (Fig. 2a,b) with long-lived ZnO luminescence represented in orange and short-lived $\mathrm{TiO}_{2}$ luminescence in blue. The 400 nm-410 nm FLIM and Zn, Ti, and $\mathrm{Ca}$ x-ray imagery are well correlated for $\mathrm{ZnO}$ in the light blue layer, and $\mathrm{TiO}_{2}$ in the white paint layer. As expected, $\mathrm{CaCO}_{3}$ is non-luminescent in this spectral band. $\mathrm{BaSO}_{4}$ also used as filler material, is also non-luminescent in the $400 \mathrm{~nm}-410 \mathrm{~nm}$ region (Fig. 2 b,c). These results demonstrate that FLIM is an additional non-destructive method to identify $\mathrm{ZnO}, \mathrm{TiO}_{2}$, and potentially a number of other pigments at sub-micron resolution in complex materials such as paintings. 


\section{References:}

[1] H. Kuhn in "Artists' Pigments", ed. R.L. Feller, (1986, National Gallery of Art), p169-186.

[2] A. Artesani et al., Appl. Phys. A 122 (2016), p. 1053.

[3] A. Artesani et al., Materials 10 (2017), p. 340.

[4] Any mention of commercial products is for information only; it does not imply recommendation or endorsement by NIST.

a

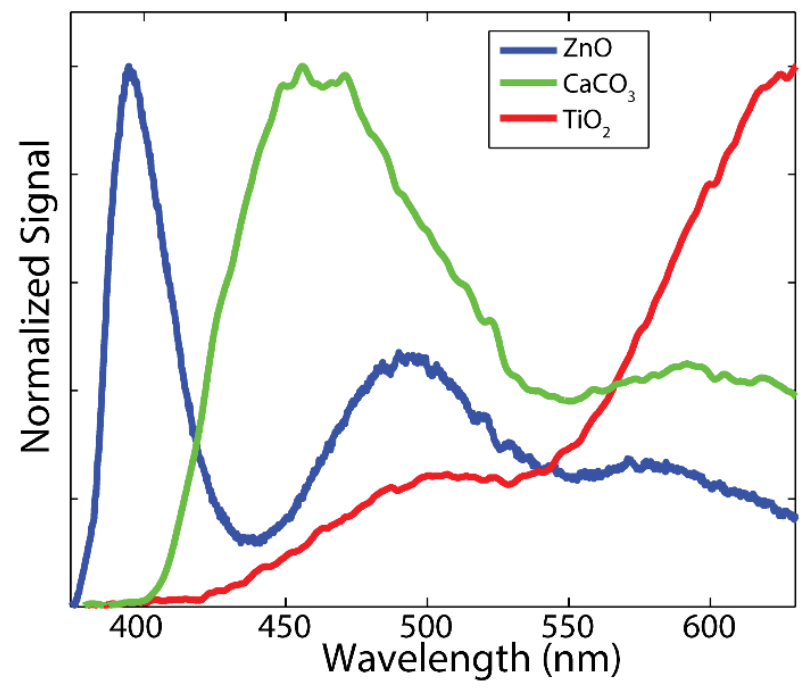

b

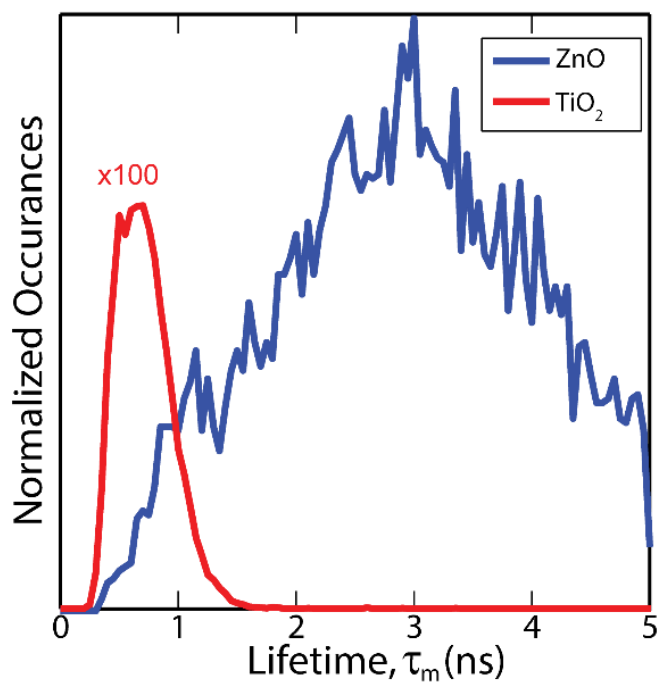

Figure 1. Spectra for separates of $\mathrm{ZnO}, \mathrm{TiO}_{2}$, and $\mathrm{CaCO}_{3}$. a) Luminescence spectra of $\mathrm{ZnO}$ (blue), $\mathrm{CaCO}_{3}$ (green), and $\mathrm{TiO}_{2}$ (red). b) Histograms of the average lifetimes for $\mathrm{ZnO}$ (blue) and $\mathrm{TiO}_{2}$ (red) for $400 \mathrm{~nm}-410 \mathrm{~nm}$. Histogram for $\mathrm{TiO}_{2}$ is scaled up by a factor $100 . \mathrm{CaCO}_{3}$ was not detectable.
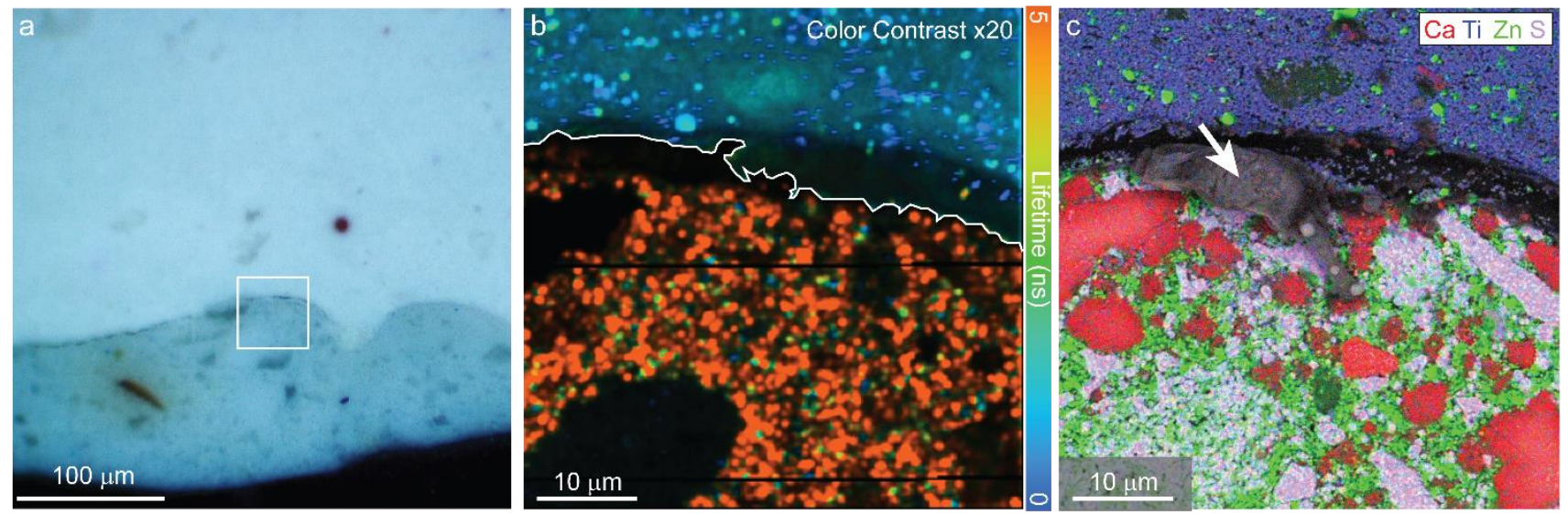

Figure 2. Painting cross-section at a layer interface. a) White light image where white square indicates the FLIM and EDS region of interest at the interface between light blue and white layers. b) FLIM image for $400 \mathrm{~nm}-410 \mathrm{~nm}$ luminescence. Orange represents $\mathrm{ZnO}$ and blue represents $\mathrm{TiO}_{2}$. Color contrast for the white region is scaled up by a factor of 20 for visualization. c) Composite $\mathrm{x}$-ray image superimposed on a backscattered electron image of the same region [Ca (red), Ti (blue), $\mathrm{Zn}$ (green), and S (lavender)]. White arrow highlights $\mathrm{C}$-rich film likely associated with varnish likely related to a previous painting surface. 